\title{
УТОЧНЕНИЕ СЕЙСМИЧЕСКОЙ ОПАСНОСТИ ДЛЯ РАЙОНА Г. ПЕРМИ
}

\author{
Д.Ю. Шулаков \\ Горный институт УрО РАН, г. Пермь
}

\begin{abstract}
Аннотация: На основании обобщения большого объема данных о сейсмической активности, сейсмогеологических условиях, геологическом и тектоническом строении окрестностей г. Перми выполнено уточнение параметров сейсмического режима, макросейсмического уравнения и выделены основные сейсмогенерирующие зоны. Эти данные послужили основой для получения вероятностной оценки уточненной сейсмической опасности для исследуемого района. Получено уравнение сейсмического режима, позволяющее оценить вероятность возникновения землетрясений различной интенсивности. Данное уравнение может использоваться для уточнения исходной сейсмичности, определяемой по картам общего сейсмического районирования.
\end{abstract}

Ключевые слова: сейсмическая опасность, сейсмический режим, сейсмогенерирующие зоны, макросейсмическое уравнение.

\section{Введение}

Согласно карте общего сейсмического районирования ОСР-2015-С, применяемой для проектирования наиболее ответственных промышленных и гражданских объектов, территория г. Перми находится в зоне 7-балльных сотрясений. В то же время используемая на данной карте градация зон с шагом в 1 балл является достаточно грубой и может приводить к заметному завышению или занижению сейсмической опасности. Для решения данной проблемы может быть проведено уточнение исходной сейсмичности, учитывающее региональные геологические, тектонические и сейсмические особенности.

Особую актуальность данная задача приобрела в связи с проектированием нового мостового перехода через р. Каму в северной части г. Перми. Для ее решения было выполнено последовательное обобщение доступных данных об особенностях региональной сейсмичности: расчет параметров сейсмического режима и коэффициентов макросейсмического уравнения для района г. Перми, уточнение границ сейсмогенерирующих зон и, как результат, получение уточненной вероятностной оценки сейсмической опасности.

\section{Сейсмический режим}

Характерной особенностью Уральского региона является то, что, с одной стороны, сейсмическая опасность здесь относительно высока и риск возникновения сильных землетрясений обязательно должен учитываться, а с другой - собственно тектонические землетрясения происходят нечасто, в связи с чем оценка параметров сейсмического режима для относительно небольших участков территории на основании исключительно каталогов сейсмической активности, как правило, затруднительна. Решение этой задачи требует комплексного анализа как исторических каталогов землетрясений, так и современных данных инструментального мониторинга в пределах региона.

Наиболее полное обобщение сведений о сейсмических событиях до 2000 года для территории Урала было реализовано в рамках исследования, выполненного в «ГИ УрО РАН» [3]. Представленный в работе каталог охватывает период с 1788 по 2000 год и включает в себя 188 событий различной природы. Только 35 из них являются достоверно определенными тектоническими событиями. Диапазон представительности этого каталога по магнитудам достаточно узок: снизу он ограничен величиной $\mathrm{M}_{\mathrm{S}}=3$. A coбытий с магнитудой $\mathrm{M}_{\mathrm{S}} \geq 5$ в каталоге насчитывается всего два. 
Начиная с 1999 г. на территории Урала силами ГИ УрО РАН (г. Пермь) в сотрудничестве с ФИЦ ЕГС РАН (г. Обнинск) была развернута и поддерживается в работе региональная сейсмологическая сеть, насчитывающая на текущий момент 12 цифровых сейсмических станций. В сравнении с историческими данными и данными инструментального этапа до 1999 г. современные сейсмические каталоги отличаются более высокой представительностью сведений по площади и магнитудам. Низкие магнитуды, в свою очередь, за счет более частой реализации обеспечивают количественную представительность данных. Тем не менее, исторический каталог остается крайне важным, поскольку содержит информацию о крупных землетрясениях, которые на территории Урала довольно редки.

Согласно [5], для уточнения сейсмического режима должны учитываться данные о землетрясениях, происходящих в радиусе 150 км от проектируемых объектов. На основании комбинирования исторического и инструментального каталогов была получена выборка из 76 землетрясений за период с 1798 по 2018 гг. На основании данной выборки был построен график повторяемости землетрясений, который в диапазоне магнитуд $\mathrm{M}_{\mathrm{L}}=1.0 \ldots 5.0$ аппроксимируется уравнением

$$
\lg N=1.2-0.73 M_{L}
$$

где $N$ - среднегодовое количество землетрясений с магнитудой $\geq M_{L}$.

В данном уравнения величина угла наклона графика (множитель перед $\mathrm{M}_{\mathrm{L}}$, так называемый $b$-value) очень хорошо согласуется с таковой для Уральского региона в целом [6], что свидетельствует о корректности полученной оценки.

\section{Региональное макросейсмическое уравнение}

В задаче адекватной оценки сейсмической опасности одним из ключевых моментов является знание модели распространения сейсмического эффекта $I$ от магнитуды $M$ и гипоцентрального расстояния $r$ в рассматриваемом регионе. Наиболее распространенной классической моделью уравнения макросейсмического поля является уравнение Шебалина- Блейка [7]:

$$
I=1.5 M-v \lg (r)+c,
$$

где $v, c$ - эмпирические коэффициенты, зависящие от геологических и сейсмотектонических особенностей региона.

При составлении карт общего сейсмического районирования (ОСР) территория Восточно-Европейской платформы, Урала и Западной Сибири выступает как единый регион с одинаковыми коэффициентами модели распространения сейсмического эффекта $(\boldsymbol{v}=3.5, c=3.0)$. Данные коэффициенты можно рассматривать как первое приближение при определении сейсмической опасности, однако для получения корректной оценки их следует уточнить.

Сильные землетрясения с макросейсмикой на рассматриваемой территории сравнительно редкие явления, поэтому за последние два десятилетия, когда возможности инструментальных наблюдений существенно выросли, их зафиксировано не более десятка. Однако расширить объем инструментальных и макросейсмических данных возможно за счет локальных сейсмологических наблюдений в районах разработки месторождений полезных ископаемых - как на территории Верхнекамского месторождения, так и на других горнодобывающих предприятиях Урала (СУБР, Высокогорский ГОК и др.).

В работе [4] приводится сводный анализ макросейсмических проявлений 22 землетрясений на территории Уральского региона за период с 1973 по 2016 гг. Кроме ин- 
формации о тектонических землетрясениях, в данной работе проанализированы данные о сейсмическом воздействии технологических взрывов на горнодобывающих объектах региона.

В результате установлено, что для приповерхностных (глубина менее 1 км) и для глубоких очагов коэффициенты в макросейсмическом уравнении (2) существенно отличаются. Для оценки сейсмической опасности интерес представляют тектонические землетрясения, очаги которых располагаются на глубинах от нескольких км до первых десятков км. Установлено, что для них коэффициенты в уравнении (2) составляют: $\boldsymbol{v}=3.17$ и $\boldsymbol{c}=2.71$. Полученное в работе [4] уравнение не только позволяет уточнить величину сейсмического эффекта землетрясений для территории Урала, но и охватывает диапазоны малых гипоцентральных расстояний и магнитуд, где ранее подобные сведения не обобщались.

\section{Выделение зон возможных очагов землетрясений}

Выделение зон возможных очагов землетрясений (ВО3), как правило, является первым этапом проведения работ по сейсмическому районированию территории. В настоящее время не существует единых нормативных документов, устанавливающих порядок выделения зон возможных очагов землетрясений, что связано как с различным геологическим строением территорий, так и с разной степенью изученности и наличием геолого-геофизической информации об исследуемом регионе.

Принятый в сейсмологии подход к выделению зон возможных очагов землетрясений заключается в анализе связи сейсмической активности и геологического строения региона, геофизических полей и современной и исторической тектонической активности. При этом невозможно выделить единственный признак, значение которого может свидетельствовать о сейсмическом режиме региона, для выделения зон возможных очагов землетрясений необходимо использовать комплекс различных параметров. Кроме того, как уже упоминалось, для сейсмически слабоактивной восточной окраины ВосточноЕвропейской платформы дополнительной сложностью является небольшое количество сейсмических событий, что затрудняет разделение зон ВОЗ по магнитудам, а также снижает точность их выделения [3].

Район пермского Прикамья расположен на границе восточной окраины ВосточноЕвропейской платформы и Предуральского краевого прогиба, и тектонически нарушения, ограничивающие эти структуры, являются сейсмически активными. Еще одной крупной региональной тектонической структурой является северо-восточная оконечность Камско-Бельского авлакогена.

Исследование сейсмической активности позволяет выделить ее четкую связь с конфигурацией геофизических полей. Так, прослеживается хорошая корреляция эпицентров землетрясений с линиями смены знака магнитных аномалий, соответствующей границе двух блоков земной коры, сдвинутых относительно друг друга. Каждое геологическое тело создает гравитационное и магнитное поле, и совместный анализ таких полей позволяет получить больше информации об исследуемом объекте. Для изучения строения региона был использован метод соотношения аномального гравитационного и магнитного полей, или метод адмиттанса. Наиболее наглядным является изучение градиента такого соотношения, что позволяет выделить не только аномалии, но и переходы между ними, детализировать и уточнить общую картину распределения геофизических полей региона [2]. Кроме того, на изучаемой территории отмечается корреляция сейсмической активности с областями современных вертикальных движений земной коры от 6 мм/год и более.

Для построения зон ВОЗ был использован алгоритм нахождения возможной связи землетрясений с геолого-геофизическим строением региона. Выбираются элементар- 
ные ячейки (учебные выборки), с центрами, привязанными к координатной сетке, при этом каждая ячейка обладает своим набором физических характеристик. Предполагается, что возможность возникновения землетрясения в этой ячейке является функцией от них.

Выделение зон ВОЗ, дифференцированных по интенсивности землетрясений, осуществлялось с помощью выбора ячеек, соответствующих искомым значениям магнитуд сейсмических событий. После выбора ячеек по определенному алгоритму проводится вычисление и нанесение их на карту с соответствующими геолого-геофизическими параметрами и оконтуривание полученных зон.

Для выделения зон ВОЗ использовалась сетевая аналитическая геоинформационная система «Геопроцессор 2», разработанная в Институте проблем передачи информации РАН. Зоны ВОЗ выделялись с использованием различных геофизических полей и их комбинаций. Выделение зон возможных очагов землетрясений проводилось с помощью учебных выборок, в которых учитывались особенности строения земной коры региона. Поскольку условия, благоприятные для возникновения землетрясений, в комплексах Западного Приуралья отличаются, для выделения всех зон возможных очагов землетрясений использовались несколько учебных выборок. Итоговая карта зон ВОЗ для окрестностей г. Перми представлена на рис. 1. Зоны ВОЗ на ней ранжированы на 2 категории в зависимости от максимальной магнитуды землетрясений $M_{\max }$.

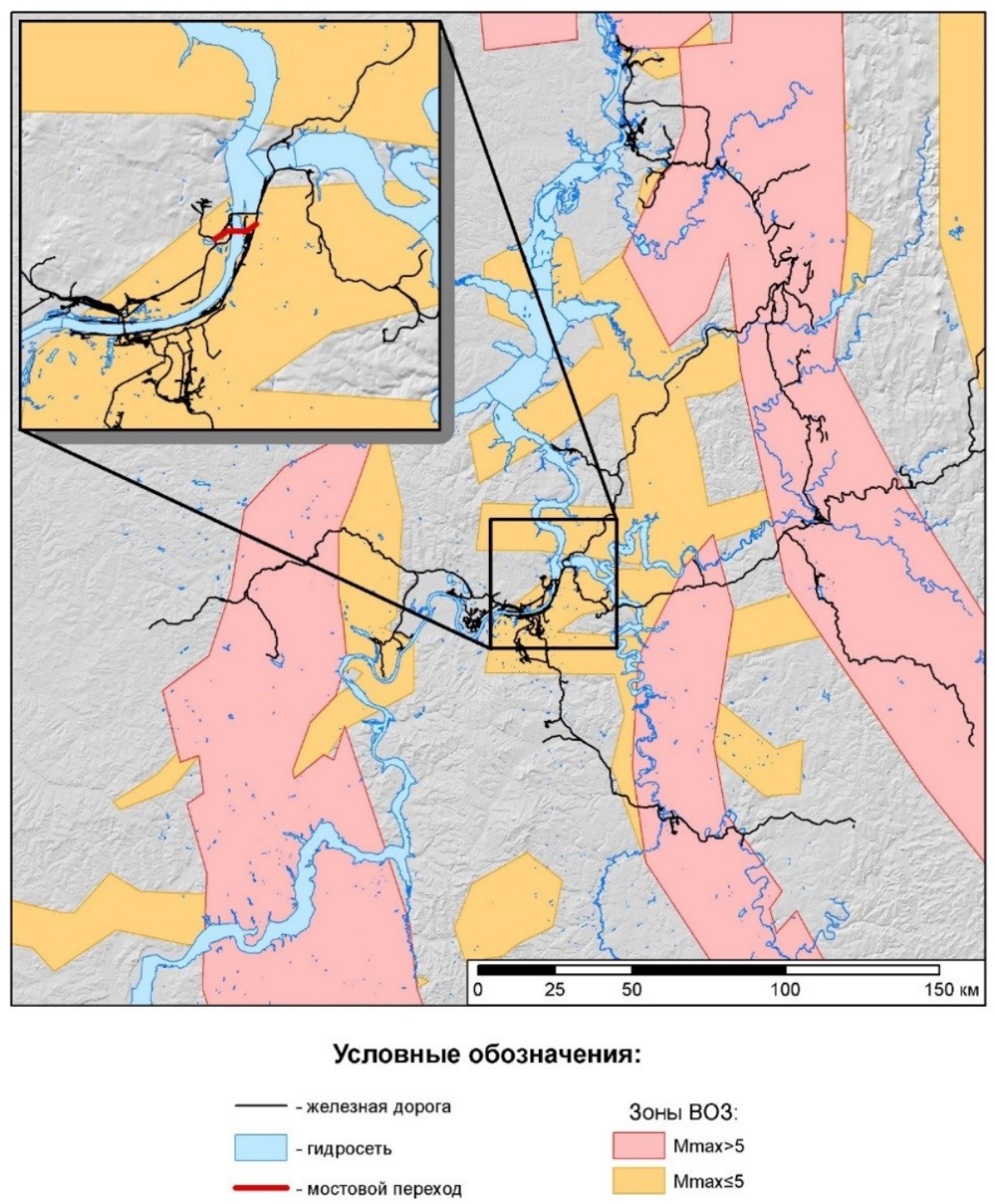

Рис. 1. Зоны возможных очагов землетрясений (ВОЗ) в окрестностях г. Перми 


\section{Оценка сейсмической опасности для района г. Перми}

Методика уточнения исходной сейсмичности (УИС) заключается в составлении для конкретного географического пункта уравнения сейсмического режима:

$$
I y m=a+b \cdot \lg T,
$$

где $a, b$ - коэффициенты уравнения сейсмического режима; $T$ - средний промежуток времени, измеряемый в годах, между землетрясениями силой Iym в месте строительства.

Коэффициенты уравнения находят на основании детальных сейсмологических исследований.

По зависимости (3) может быть определена уточненная сила землетрясения Iym с точностью до 0.1 балла применительно к ровным участкам местности, сложенным средними по сейсмическим свойствам грунтами, для заданного $T$ в интервале от 500 до 5000 лет.

Основой для расчетов уточненной сейсмической опасности являются следующие данные, характеризующие сейсмотектонические и геологические особенности региона:

- средняя повторяемость землетрясений в радиусе 150 км описывается уравнением (1);

- величина сейсмического воздействия от землетрясения может быть описана региональным вариантом уравнения Шебалина-Блейка (2) с коэффициентами $v=3.17$ и $c=2.71$;

- землетрясения могут происходить в пределах региональных зон ВОЗ, ранжированных по максимальной возможной магнитуде землетрясения;

- максимальная магнитуда землетрясения в зонах BO3 с $\mathrm{M}_{\max }>5$ принята $\mathrm{M}_{\mathrm{L}}=6$.

В связи с низким уровнем сейсмической активности для оценки сейсмической опасности на рассматриваемой территории наиболее применим вероятностный метод. Сущность этого метода заключается в вычислении вероятности $\lambda$, при которой уровень колебаний грунта $I_{0}$ будет достигнут или превышен величиной $I[1]$ :

$$
\lambda\left(I \geq I_{0}\right)=\sum_{i=1}^{N_{s}} v_{i} \sum_{j=1}^{N_{M}} \sum_{k=1}^{N_{R}} P\left[I(m, r) \geq I_{0} \mid m_{j}, r_{k}\right] P\left(M_{i}=m_{j}\right) P\left(R_{i}=r_{k}\right)
$$

где $f_{M_{i}}(r)$ - функция плотности вероятности магнитуд, описывающая вероятность события с магнитудой, заданной в определенных пределах; $f_{R_{j}}(r)$ - функция плотности вероятности расстояния от гипоцентра до исследуемого участка; $P[I(m, r) \geq$ $\left.I_{0} \mid m_{j}, r_{k}\right]$ - вероятность превышения интенсивности $I_{0}$, в случае, если землетрясение магнитудой $m$ произошло на расстоянии $r$; $v_{i}$ - частота возникновения землетрясений магнитудой больше минимальной $m_{\min }$ для отдельного источника $i$ из общего числа источников $N_{S}$.

Таким образом, итоговая вероятность превышения заданной интенсивности колебаний в течение какого-то периода времени представляется как сумма вероятностей превышения этой интенсивности от землетрясений в каждой из зон ВОЗ.

Как видно из рис. 1, г. Пермь находится внутри зоны ВО3 с $\mathrm{M}_{\max } \leq 5$, а расстояние до ближайшей зоны ВО3 с $\mathrm{M}_{\max }>5$ составляет около 35 км. На основании изложенной выше методики был выполнен расчет средней повторяемости колебаний с интенсивностью от 5 до 7 баллов по шкале MSK-64. В графическом виде данные результаты представлены на рис. 2.

Как видно из рисунка, расчетные значения с высокой достоверностью $(R=0.996)$ аппроксимируются уравнением сейсмического режима

$$
I=(1.50 \cdot \lg T+0.93) \pm 0.08
$$


Для особо ответственных промышленных объектов базовая сейсмичность определяется по карте С общего сейсмического районирования ОСР-2015. Согласно этой карте, она составляет 7 баллов. Соответственно, уточненная сила землетрясения для данного объекта определяется для периода повторяемости $T=5000$ лет. Согласно уравнению сейсмического режима (4), уточненное значение сейсмичности для данного участка составляет $I=6.5$ балла шкалы MSK-64, а поправка, учитывающая сейсмический режим местности $\delta I . . p .=-0.5$.

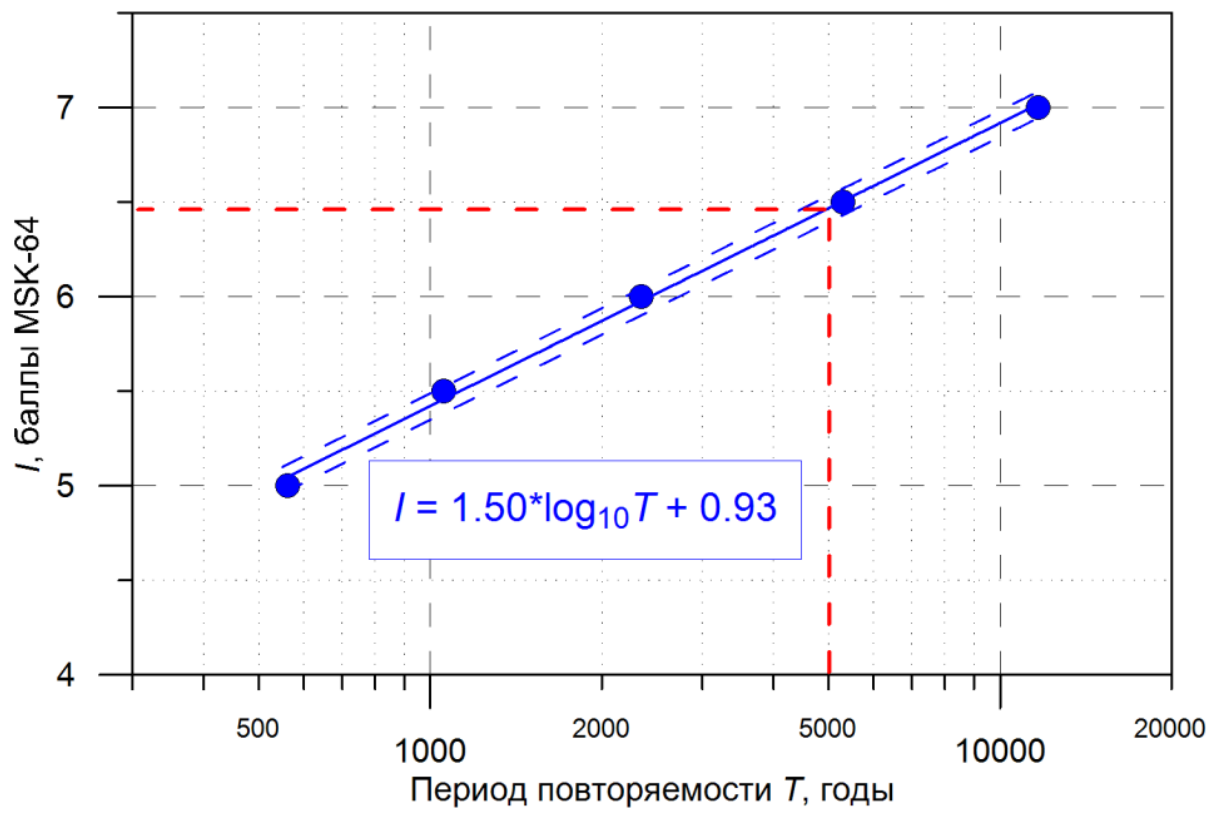

Рис. 2. График сейсмического режима для северной части территории г. Перми

\section{Выводы}

На основании детального анализа сейсмической, геологической и тектонической информации впервые получена уточненная вероятностная оценка сейсмической опасности для территории г. Перми. Для периода повторяемости 5000 лет (карта ОСР-2015C) она составляет 6.5 балла МСК-64, для периода повторяемости 1000 лет (ОСР-2015В) - 5.4 балла. Данные оценки хорошо согласуются с картами общего сейсмического районирования (отклонение не превышает 0.5 балла), хотя и получены на независимом от них наборе данных и с использованием другой методики расчета.

Полученные значения могут использоваться в качестве исходной сейсмичности при проектировании строительства зданий и сооружений, а также при сейсмическом микрорайонировании.

Исследование выполнено при финансовой поддержке Программы ФНИ, проект № 0422-2019-0146-С-02 (регистрационный номер темы НИОКТР: AAAA-A18-118040690028-5)

\section{БИБЛИОГРАФИЧЕСКИЙ СПИСОК}

1. Jessica G. Probabilistic seismic hazard analysis - an introduction to theoretical basis and applied methodology. - Текст электронный. - URL:http://www.roseschool.it/files/get/id/4440, свободный.

2. Баранов Ю.В. Выделение и дифференциация зон возможных очагов землетрясений Западного Приуралья // Стратегия и процессы освоения георесурсов: сб. науч. тр. Вып. 15 / ГИ УрО РАН. - Пермь, 2017. - C. 198-201.

3. Блинова Т.С. Прогноз геодинамически неустойчивых зон. - Екатеринбург: УрО РАН, 2003. - 163 с. 
4. Дягилев Р. А. Макросейсмика техногенных землетрясений Урала // Горный информационноаналитический бюллетень (научно-технический журнал). - 2017. - № 3. - С. 292-304.

5. СП 269.1325800.2016 Транспортные сооружения в сейсмических районах. Правила уточнения исходной сейсмичности и сейсмического микрорайонирования. Дата введения 2017-06-17. - М., 2016. - 77 с.

6. Уломов В.И., Шумилина Л.С. Проблемы сейсмического районирования территории России. - М.: ВНИИНТПИ Госстроя России, 1999. - 56 с.

7. Шебалин Н.В. Методы использования инженерно-сейсмологических данных при сейсмическом районировании // Сейсмическое районирование СССР. - М., 1968. - С. 95-111.

\title{
ПРОЯВЛЕНИЕ ФРАНСКО-ТУРНЕЙСКИХ РИФОГЕННЫХ МАССИВОВ В ПЛОТНОСТНОМ СТРОЕНИИ ВЕРХНЕЙ ЧАСТИ РАЗРЕЗА СОЛИКАМСКОЙ ВПАДИНЫ
}

\author{
Г.П. Щербинина \\ Горный институт УрО РАН, г. Пермь
}

\begin{abstract}
Аннотация: Гравиметрической съемкой, проводимой на Верхнекамском месторождении калийных солей (Соликамская впадина Предуральского прогиба), установлено, что породные толщи верхней части разреза обладают плотностной неоднородностью, не связанной с литологией. Картины плотностной неоднородности обусловлены разными причинами. Одна из них, формирующая закономерный рисунок в расположении локальных аномалий - присутствие франско-турнейских рифогенных массивов. Гравиметрическая съемка показала, что в верхней части осадочного чехла по контуру франско-турнейских массивов наблюдаются локальные разуплотненные участки в виде цепочек. Снижение плотности на локальных участках достигает $2 \%$.
\end{abstract}

Ключевые слова: гравиметрия, плотность пород, рифогенный массив, плотностная картина.

Франско-турнейская карбонатная толща в Соликамской впадине Предуральского прогиба залегает на глубинах от 1.8 до 2.5 км. Выше по разрезу на глубине 200-700 м располагается толща солей, к которой приурочено Верхнекамское месторождение калия. Франско-турнейская толща содержит рифовые постройки с размерами в поперечнике 5-6 км. Они имеют преимущественно изометричную форму в плане и сложены органогенными карбонатами, обладающими жестким каркасом и характе-

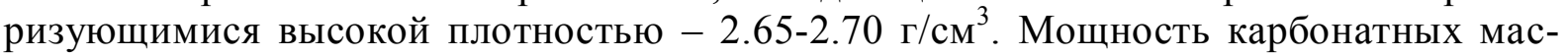
сивов достигает 500-550 м. Синхронная им слоистая толща представлена межрифовыми отложениями - обломочными карбонатами, глинистыми и битуминозными карбонатами, характеризующимися средней пониженной плотностью $\left(2.37-2.45 \mathrm{r} / \mathrm{cm}^{3}\right)$. Межрифовые отложения за счет глинистой составляющей в продолжение геологической истории при накоплении перекрывающих отложений уплотнялись. Эффект уплотнения проявился в сокращении их мощности и формировании в вышележащих толщах над рифами структур облекания, которые являются в данном регионе основными нефтесодержащими структурами. Современная мощность франскотурнейской толщи в межрифовых пространствах на Березниковском палеоплато составляет 300-350 м. В соседних с палеоплато впадинах мощность франскотурнейской толщи 150-200 м.

Период уплотнения межрифовых осадков растянулся на продолжительное время. Например даже в подошве соляной лунежской толщи над рифовыми массивами в настоящее время наблюдаются структуры облекания, хотя и слабо выраженные.

Плотностное гравиметрическое моделирование показало, что перекрывающие толщи карбона и перми над франско-турнейскими рифогенными массивами характеризуются 